\title{
What maternal factors influence the diet of 2-year-old children living in deprived areas? A cross-sectional survey
}

\author{
lain K Crombie ${ }^{1, *}$, Kirsty Kiezebrink ${ }^{1} \uparrow$, Linda Irvine ${ }^{1}$, Wendy L Wrieden ${ }^{2} \ddagger$, \\ Vivien Swanson ${ }^{3}$, Kevin Power ${ }^{4}$ and Peter W Slane ${ }^{5}$ \\ 'Department of Public Health, University of Dundee, Mackenzie Building, Kirsty Semple Way, Dundee DD2 4BF, \\ UK: ${ }^{2}$ Centre for Public Health Nutrition, Department of Medicine, University of Dundee, Dundee, UK: \\ ${ }^{3}$ Department of Psychology, University of Stirling, Stirling, UK: ${ }^{4}$ Department of Clinical Psychology, NHS Tayside, \\ Dundee, UK: ${ }^{5}$ Erskine Practice, Arthurstone Medical Centre, Dundee, UK
}

Submitted 2 October 2007: Accepted 3 September 2008: First published online 30 September 2008

\begin{abstract}
Objective: To investigate the maternal factors associated with poor diet among disadvantaged children.

Design: Survey of 300 mothers of 2-year-old children from areas of high deprivation in Scotland (response rate $81 \%$ ). A diet quality score was derived from reported consumption of carbohydrates, protein, fruit and vegetables, dairy products and restriction of sugary fatty foods.

Results: Most children (85\%) were classified as having a poor quality diet (low diet quality score). Mothers' general knowledge about healthy eating was high, but did not predict the quality of the children's diet. Lower frequencies of food preparation and serving, such as cooking with raw ingredients, providing breakfast daily and the family eating together, were also associated with a poorer diet. Regression modelling identified five significant factors. An increased risk of a poor diet was associated with mothers being unlikely to restrict sweets ( $\mathrm{OR}=21 \cdot 63,95 \% \mathrm{CI} 2 \cdot 70,173 \cdot 30$ ) or finding it difficult to provide $2-3$ portions of fruit daily (OR $=2 \cdot 94,95 \%$ CI $1 \cdot 09$, 7.95). Concern that the child did not eat enough increased the risk of a poor diet $(\mathrm{OR}=2 \cdot 37,95 \% \mathrm{CI} 1 \cdot 09,5 \cdot 16)$. Believing a healthy diet would help the child eat more reduced the risk of having a poor diet $(\mathrm{OR}=0 \cdot 28,95 \% \mathrm{CI} 0 \cdot 11,0 \cdot 74)$, as did providing breakfast daily $(\mathrm{OR}=0 \cdot 22,95 \% \mathrm{CI} 0 \cdot 05,0 \cdot 99)$.

Conclusions: Interventions to improve children's diet could promote more positive intentions about preparing and serving of foods, particularly of specific meals at which the family eats together. The benefits of these behaviours to the child (improved diet, weight control) should be emphasised.
\end{abstract}

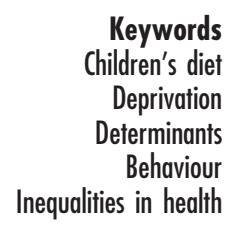

Keywords

erminants

Behaviour

Inequalities in health
Poor diet is associated with an increased risk of obesity, CHD and diabetes ${ }^{(1)}$. The increasing prevalence of obesity and diabetes in children and adolescents is a major public health problem ${ }^{(2)}$. Current dietary problems include the regular consumption of snacks, sweets, soft drinks and fatty foods, and the low consumption of fruit and vegetables ${ }^{(3,4)}$. Socially disadvantaged groups are at particular risk of having a poor diet ${ }^{(5,6)}$. Low income is an important factor for diet but it is not the only determinant of dietary behaviour. The recently published national survey on low income and $\operatorname{diet}^{(7)}$ showed that the most deprived $15 \%$ of the population were less likely to consume

$\uparrow$ Current address: Division of Health and Food Sciences, University of Abertay, Dundee, UK.

\$ Current address: Health Services Research Unit, University of Aberdeen, Health Sciences Building, Aberdeen, UK. wholemeal bread and vegetables and more likely to eat more processed meat, fat, spreads and oil and sugar.

Parents play a major role in determining dietary behaviour in children ${ }^{(8,9)}$, with factors such as parental age, diet, education, occupation and health knowledge being important ${ }^{(8,10-15)}$. Other factors could include differences in purchasing patterns and the extent to which parents restrict their children's consumption of sweet foods, soft drinks and snacks ${ }^{(16)}$. A particularly interesting finding is that the variety of foodstuffs to which young children are exposed is an important determinant of subsequent diet. Children exposed to a limited range of foodstuffs may develop food neophobia, the dislike of new foods ${ }^{(17,18)}$. The extent to which foodstuffs are presented in a positive or negative context also influences diet in children ${ }^{(19)}$.

The design of interventions to improve diet in disadvantaged children will require a better understanding 
of the factors that influence eating behaviour. The present study investigates in detail the role of maternal factors in determining poor diet among disadvantaged 2-year-old children. It focused on 2-year-olds because mothers have considerable influence on what their children eat at this age and because this is the time when eating behaviour is being established ${ }^{(12,20)}$.

\section{Methods}

The Tayside and Fife Committees on Medical Research Ethics approved the study (project reference 04/ S1401115). The Scottish Index of Multiple Deprivation (SIMD) ${ }^{(21)}$ was used to identify families living in areas of high deprivation. Ten general practices in Dundee and Fife situated in the two most deprived deciles were recruited. They identified a random sample of children aged 2 years with low SIMD scores. General practices were reimbursed for the time spent by practice staff identifying potential participants. To provide precise estimates of the proportions of women holding particular attitudes and beliefs, the sample size was calculated by specifying the desired size of the $95 \%$ confidence intervals. To obtain a $95 \%$ confidence interval of $\pm 5 \%$ required a sample of 300 women. A total 372 mothers had to be approached to yield the desired final sample.

Letters of invitation signed by a general practitioner were posted to the women together with a postcard to be returned if they did not wish to take part. Only three women opted out when first contacted by their general practitioner. Women who did not opt out were contacted by the researcher to discuss the study and to arrange an appointment for the interview. Eighteen women could not be contacted and forty-six refused to take part when contacted by the researcher. Five women were excluded after recruitment because they did not meet the entry criteria. In total 300 were successfully interviewed (response rate of $81 \%$ ).

Questionnaire data were collected from 9 November 2005 to 13 October 2006. The questionnaire was developed using: a social cognition approach, particularly the Theory of Planned Behaviour ${ }^{(22)}$; previously used dietary questionnaires ${ }^{(23-26)}$; a literature review; and the findings from six focus groups conducted with mothers living in areas of high deprivation (details available from authors). Mothers were interviewed at home using a structured questionnaire displayed on a laptop computer. Each screen page contained only a few questions and most screens were illustrated with relevant computer graphics. The questionnaire was completed by the researcher but interviewees were shown the questions on the computer screen. For questions on food groups the graphics displayed the types of food within each group. As many of the questions had multiple choice answers, the use of screen displays gave interviewees the opportunity to view the question and possible answers while considering their responses. Most of the knowledge and belief questions used a 5-point Likert scale. Where appropriate the stem questions were derived from the Theory of Planned Behaviour. For example, on the subject of giving the child breakfast daily, some questions were 'I plan to give breakfast every day...' (options: strongly agree to strongly disagree); 'Giving breakfast every day is...' (options: very important to not at all important); 'Other people think I should give breakfast every day...' (options: strongly agree to strongly disagree).

Assessment of the children's diet was based on national dietary recommendations. The Caroline Walker Trust recommends that a varied diet for under-fives should include food from the main four food groups every day ${ }^{(27)}$. These are reinforced, and extended to include limits on high-fat/high-sugar foods, by Scottish nutritional guidance for early years ${ }^{(28)}$ and the National Food Guide Balance of Good Health ${ }^{(29)}$, recently updated as the Eatwell Plate ${ }^{(30)}$. Children were allocated a dichotomous score based on whether or not they achieved a balance of the four major food groups and a limited amount of fatty and sugary foods. Children were classified as having a poor diet if they did not achieve all of the following:

1. Two or more portions of bread, other cereals or potatoes daily.

2. Two or more portions of fruit or vegetables daily.

3. One or more portions of dairy products daily.

4. One or more portions of meat, fish or alternatives daily.

5. No more than two high-fat or high-sugar snacks daily.

Modest criteria were set on the number of portions because there is evidence that few children attain the recommendations, particularly the guideline for fruit and vegetables $^{(5)}$.

Data were analysed using the SPSS for Windows statistical software package (SPSS Inc., Chicago, IL, USA). Logistic regression analysis was used to assess the relative importance of variables that predicted the quality of the diet eaten by the children. Variables were coded such that an increased odds ratio indicated an increased likelihood of a poor diet. Factors that were significant in univariate analysis were fitted into a model using forward selection (entry criterion $P<0.05$ ) to identify factors that exerted statistically significant independent effects in determining the diet of the children.

\section{Results}

Three hundred mothers of children aged 2 years were interviewed. The age range of mothers was 18 to 34 years, with more than $70 \%$ aged between 22 and 29 years (Table 1). Most lived in council housing (81\%), $43 \%$ of mothers reported that no other adult lived in the home and (91\%) were not in employment. Only $22 \%$ of children had ever been breast-fed and $60 \%$ of mothers were 
smokers. Over $80 \%$ of the children watched television for $>4$ h daily and only $22 \%$ regularly played outdoors.

The quality of the children's diet was mixed. All children had dairy products daily and nearly all had a portion of a protein-rich food daily. However, most (91\%) ate processed meat two or more times weekly. Almost all children (95\%) had breakfast cereals at least five times weekly, although $43 \%$ reported that this consisted of high-sugar breakfast cereals. Only $12 \%$ of children met the recommended five portions of fruit and vegetables daily, with $47 \%$ eating one or more portions of vegetables daily. Less than $1 \%$ of children ate fish every week.

To explore predictors of the quality of the children's diet a scoring system was developed. This was based on current dietary recommendations for the four main food groups ${ }^{(27)}$ and the advice to restrict consumption of sugary fatty snacks (Table 2). Modest targets were set for the individual components. Many children achieved individual targets, but only forty-five children (15\%) achieved all five (Table 2).

The level of mothers' general knowledge about food recommendations and the benefits of a healthy diet was very high (Table 3). For example, 100\% knew they should eat more fruit, vegetables and complex carbohydrates and

Table 1 Sociodemographic characteristics of participants: mothers ( $n$ 300) of 2-year-old children from areas of high deprivation in Scotland, November 2005-October 2006

\begin{tabular}{lrr}
\hline Factor & $n$ & $\%$ \\
\hline Mother's age & & \\
18-21 years & 45 & 15 \\
$22-25$ years & 109 & 36 \\
$26-29$ years & 130 & 43 \\
30-34 years & 16 & 5 \\
Housing tenure & & \\
Council house & 243 & 81 \\
Privately rented & 38 & 13 \\
Owner occupied & 8 & 3 \\
Not known & 11 & 4 \\
Mother is the only adult in the household & 128 & 43 \\
Mother's employment status & & \\
Not in employment & 272 & 91 \\
Part time employment & 28 & 9 \\
Mother smokes & 181 & 60 \\
Child ever breast-fed & 66 & 22 \\
\hline
\end{tabular}

less fried foods and confectionery. They were also well informed about the links between diet (saturated fats, fruit and vegetables, sugar) and health outcomes. Almost all mothers believed a healthy diet was good for their child both in the short term (better for their teeth and improved behaviour) and the long term (grow up strong). None of these knowledge factors was significantly associated with the risk of a poor diet (low diet quality score).

As well as questions on general dietary knowledge, mothers were asked about knowledge of specific dietary recommendations (Table 4). The risk of a poor diet was significantly increased if mothers thought the recommendations were that children should eat less than five pieces of fruit and vegetables (OR $=3 \cdot 05,95 \%$ CI $1 \cdot 35$, $6 \cdot 92)$ or eat more than two snacks daily (OR $=17 \cdot 54,95 \%$ CI $2 \cdot 31,142 \cdot 86)$. The children of mothers who were confident of their knowledge about healthy eating had a significantly reduced risk of a poor diet, whereas risk was increased if mothers thought advice on healthy eating was confusing. When presented with five common leaflets on nutrition for young children, $62 \%$ of mothers

Table 3 Knowledge of food recommendations and the benefits of healthy food: mothers $(n 300)$ of 2-year-old children from areas of high deprivation in Scotland, November 2005-October 2006

\begin{tabular}{lrr}
\hline & $n^{*}$ & $\%$ \\
\hline Mothers correctly identifying that experts recommend & & \\
More bread, pasta, rice, potatoes & 300 & 100 \\
More green vegetables & 300 & 100 \\
More salad & 300 & 100 \\
More fruit & 300 & 100 \\
Less fried foods & 300 & 100 \\
Less crisps & 300 & 100 \\
Less confectionery & 300 & 100 \\
Knowledge of the relationship between food and & & \\
disease & & \\
$\quad$ Less saturated fat would prevent heart disease & 300 & 100 \\
More fruit and vegetables could help prevent & 266 & 89 \\
cancer & & \\
Less sugar will help maintain a healthy weight & 300 & 100 \\
Perceived benefits to the child of a healthy diet & & \\
$\quad$ Help them to behave better & 275 & 92 \\
Better for their teeth & 300 & 100 \\
Help them grow up strong & 295 & 98 \\
$\quad$ Better for their heart & 300 & 100 \\
\hline *Number of mothers stating. & &
\end{tabular}

Table 2 Components of dietary quality score developed to assess the diet of 2-year-old children ( $n$ 300) from areas of high deprivation in Scotland, November 2005-October 2006

\begin{tabular}{lrr}
\hline Food type and frequency of consumption & $n^{\star}$ & $\%$ \\
\hline Eats two or more portions of bread, other cerealst and potatoes daily & 203 & 68 \\
Eats two or more portions of fruit or vegetables daily & 184 & 61 \\
Eats one or more portions of dairy products daily§ & 300 & 100 \\
Eats one or more portions of meat, fish or alternatives dailyll & 272 & 91 \\
Eats no more than two high-fat or high-sugar snacks daily & 104 & 34 \\
Achieves all five of the above & 45 & 15 \\
\hline
\end{tabular}

${ }^{*}$ Number of children achieving.

tIncludes breakfast cereals, rice and pasta.

fln calculating this composite score all types of fruit and vegetables were included (i.e. frozen, fresh, etc.). Fruit juice could only contribute to a maximum of one portion daily. Pulses have not been included here as they have been included in the meat, poultry and alternatives calculation. $\S$ All milk was included irrespective of fat content or type (i.e. cow's, soya, goat's, etc.).

IIAll types of meat and poultry were included whether processed on non-processed. 
Table 4 Maternal factors which predict the quality of the child's diet: mothers ( $n 300)$ of 2-year-old children from areas of high deprivation in Scotland, November 2005-October 2006

\begin{tabular}{|c|c|c|c|}
\hline & \multirow[b]{2}{*}{$\%$ agree } & \multicolumn{2}{|c|}{ Risk of poor diet if respondents agree } \\
\hline & & OR & $95 \% \mathrm{Cl}$ \\
\hline \multicolumn{4}{|l|}{ Knowledge } \\
\hline Thinks recommendation for fruit and vegetables is $<5$ portions daily & 29 & 3.05 & $1 \cdot 35,6 \cdot 92$ \\
\hline Thinks recommendation for snacks is $>2$ daily & 20 & $17 \cdot 54$ & $2 \cdot 31,142 \cdot 86$ \\
\hline I know a lot about healthy eating for children & 35 & 0.45 & $0.24,0.86$ \\
\hline There are a lot of confusing messages about what a healthy diet is & 93 & $8 \cdot 84$ & $3 \cdot 42,22 \cdot 89$ \\
\hline Unawareness of any of five nutrition leaflets for young children & 62 & $3 \cdot 17$ & $1 \cdot 29,7 \cdot 81$ \\
\hline \multicolumn{4}{|l|}{ Concerns about how much the child eats } \\
\hline I sometimes worry that my child does not eat enough & 17 & $6 \cdot 32$ & $3 \cdot 15,12 \cdot 68$ \\
\hline Providing a healthy diet is difficult because it won't fill them up & 31 & 5.95 & $2 \cdot 04,17 \cdot 41$ \\
\hline A healthy diet would make no difference to their weight & 95 & $4 \cdot 75$ & $1 \cdot 56,14 \cdot 43$ \\
\hline Providing a healthy diet is important because it helps them eat more & 10 & $0 \cdot 11$ & $0.005,0.27$ \\
\hline I sometimes worry that my child eats too much & 97 & $0 \cdot 10$ & $0.02,0.41$ \\
\hline \multicolumn{4}{|l|}{ Preparation and serving of food to children } \\
\hline Providing a healthy diet is difficult because I have a busy lifestyle & 35 & 3.07 & $1 \cdot 34,7 \cdot 02$ \\
\hline Household never ate a main meal together in last week & 32 & $4 \cdot 05$ & $1.55,10 \cdot 62$ \\
\hline Mother does not make soup & 93 & $7 \cdot 18$ & $2 \cdot 90,17 \cdot 82$ \\
\hline Child provided with breakfast daily in the last week & 77 & $0 \cdot 21$ & $0.06,0.70$ \\
\hline Mother almost never offers previously rejected food to the child & 45 & $7 \cdot 22$ & $2 \cdot 97,17 \cdot 55$ \\
\hline \multicolumn{4}{|l|}{ Mothers' views on the provision of foods } \\
\hline Is not likely to limit sweets every day & 41 & $39 \cdot 73$ & $5 \cdot 39,292 \cdot 78$ \\
\hline Is not likely to provide $2-3$ portions of fruit daily & 47 & $7 \cdot 08$ & $2 \cdot 10,23 \cdot 79$ \\
\hline Is not likely to provide $2-3$ portions of vegetables daily & 47 & 3.01 & $1 \cdot 20,7 \cdot 53$ \\
\hline Limiting sweets every day is not important & 36 & $31 \cdot 81$ & $4 \cdot 32,234 \cdot 50$ \\
\hline Providing $2-3$ portions of fruit daily is not easy & 59 & $9 \cdot 98$ & $4 \cdot 03,24 \cdot 71$ \\
\hline Limiting sweets every day is not easy & 47 & $4 \cdot 16$ & $1 \cdot 41,12 \cdot 26$ \\
\hline
\end{tabular}

claimed that they had not seen any of them before and this modestly increased the risk of a poor diet.

The mothers' perception of the amount which the toddler ate was also important. Concerns about the child not eating enough and the belief that a healthy diet would make no difference to their weight significantly increased the risk of a poor diet (Table 4). Consistent with this, concern that the child sometimes ate too much reduced the risk of a poor diet.

Access to shops was not a problem, as all mothers did the majority of their shopping at a supermarket and threequarters could buy fruit and vegetables of good quality. Only a few mothers reported that availability of cooking facilities (1\%) and storage space (9\%) were barriers to providing healthy meals. Most mothers reported that they could make typical family meals such as soup, mince and potatoes and spaghetti bolognaise, but less than half reported being able to make curry, fruit salad or pizza. Many fewer mothers actually made these foods; for example, $82 \%$ could make soup but only $7 \%$ did so. The children whose mothers did not make soup were at an increased risk of a poor diet (OR $=7 \cdot 18,95 \%$ CI $2 \cdot 90,17 \cdot 82)$. Reporting a busy lifestyle increased the risk of a poor diet $(\mathrm{OR}=3 \cdot 07,95 \% \mathrm{CI}$ $1 \cdot 34,7 \cdot 02)$. Children whose families had not eaten a meal together in the previous week had an increased risk of a poor diet $(\mathrm{OR}=4 \cdot 05,95 \% \mathrm{CI} 1 \cdot 55,10 \cdot 62)$. Children who had breakfast daily in the preceding week were much less likely to have a poor diet $(\mathrm{OR}=0 \cdot 21,95 \%$ CI $0 \cdot 06,0 \cdot 70)$. Never offering previously rejected foods also increased the risk of a poor diet $(\mathrm{OR}=7 \cdot 22,95 \%$ CI $2 \cdot 97,17 \cdot 55)$.
Mothers were asked about their views on the provision of three key food items (providing fruit and vegetables and limiting sweets). They were asked in turn how important it was to provide fruit and vegetables and to limit sweets, how easy it was to do it and how likely it was that they would do so. These items were powerful predictors of dietary quality. The most powerful were thinking it was unlikely that they would limit sweets (OR $=39 \cdot 73,95 \%$ CI 5·39, 292.78) and thinking it was not important to limit sweets $(\mathrm{OR}=31 \cdot 81$, $95 \%$ CI $4 \cdot 32,234 \cdot 50)$. Other important factors were stating that providing 2-3 portions of fruit daily was not easy $(\mathrm{OR}=9.98,95 \% \mathrm{CI} 4 \cdot 03,24 \cdot 71)$ and reporting that they were not likely to provide $2-3$ portions of fruit daily (OR $=7 \cdot 08$, 95\% CI $2 \cdot 10,23 \cdot 79)$.

In multiple logistic regression analysis, five factors were found to exert statistically significant independent effects on the quality of young children's diet (Table 5). These covered mothers' perceptions of their control over the child's diet (unlikely to limit sweets and providing fruit every day is not easy); concerns about what the child eats (that a healthy diet will help the child eat more and mothers' concern that the child does not eat enough); and the serving of meals (providing breakfast daily). The final model showed a good fit to the data (Hosmer-Lemeshow goodness-of-fit test, $\chi^{2}=4 \cdot 21$, df $\left.=7, P=0 \cdot 75\right)$.

\section{Discussion}

The study successfully conducted interviews with a high proportion of a sample of mothers living in socio-economically 
Table 5 Final model of maternal factors influencing the quality of children's diet: mothers $(n 300)$ of 2-year-old children from areas of high deprivation in Scotland, November 2005-October 2006

\begin{tabular}{lcc}
\hline & \multicolumn{2}{c}{ Risk of having a poor diet } \\
\cline { 2 - 3 } Factor & OR & $95 \% \mathrm{Cl}$ \\
\hline Not likely to limit sweets every day & $21 \cdot 63$ & $2 \cdot 70,173 \cdot 30$ \\
Reporting that it is not easy to provide 2-3 portions of fruit daily & $2 \cdot 94$ & $1 \cdot 09,7 \cdot 95$ \\
Believing a healthy diet will help the child eat more & $0 \cdot 28$ & $0 \cdot 11,0 \cdot 74$ \\
Worrying that the child does not eat enough & $2 \cdot 37$ & $1 \cdot 09,5 \cdot 16$ \\
Eating breakfast daily & $0 \cdot 22$ & $0 \cdot 05,0 \cdot 99$ \\
\hline
\end{tabular}

deprived areas. It supports previous research that many disadvantaged children have a poor diet ${ }^{(5,6,31)}$. It also shows the importance of mothers' knowledge, beliefs and intentions in determining the diet of 2-year-old children living in areas of high deprivation. The most powerful predictor of poor diet quality was whether the mother intended to limit sweets, but regular mealtimes and concerns about how much the child eats were also important. As recently reported elsewhere ${ }^{(7,32)}$, we found that access to shops and availability of cooking facilities were not associated with diet quality (low diet quality score).

Exposure to a wide range of foodstuffs in early childhood encourages the child to have a varied diet later ${ }^{(19)}$. It is suggested that a child needs to be given a new foodstuff over ten times before initial resistance is overcome $^{(20)}$. Thus it is disappointing that in the present study almost half of mothers never offered previously rejected foods and this factor significantly increased the risk of a poor diet in the univariate analysis. Encouraging mothers to repeatedly try rejected foods would seem an essential component of any strategy to improve the diet of young children. Such an approach should also explain how children learn food preferences ${ }^{(33)}$.

The results of the study suggest that guidance to improve the children's diet should address the control which the mother exerts. This needs to be approached with care as there is strong evidence that restricting the amount of food results in overeating and overweight ${ }^{(34)}$. For example, restricting children's access to high-sugar foods can foster a preference for very sweet foods with increased consumption when not strictly supervised ${ }^{(35)}$. One alternative, encouraging the child to eat healthy foods while offering a choice of eating, was associated with an increased consumption of fruit and vegetables ${ }^{(36)}$. It is also thought that a child can associate foodstuffs with the context in which it is eaten ${ }^{(19)}$. Thus parents could provide encouragement to eat healthy foods ${ }^{(37)}$ and praise for their consumption $^{(38)}$.

A separate issue is the planning and organisation of mealtimes. The present study found that half of the mothers seldom plan their children's meals. This could result in an over-reliance on convenience foods, supplied on the demand of a hungry child. The study has also shown that several planning factors are significant in the univariate analysis and one, regular breakfast, was retained in the final model. Family mealtimes have been shown to be important for the quality of adolescents' diet ${ }^{(39)}$. Thus encouragement to plan regular meals, particularly when the family eat together, could form part of a strategy to improve diet.

The worry that the child does not eat enough is a challenge for improving the child's diet. For most of human history parents have been concerned with ensuring the child had enough to eat, a view that may persist ${ }^{(20)}$. This concern could lead the mothers to supply any type of food, however healthy or unhealthy, to ensure the child is not undernourished. Furthermore, only a few mothers were concerned about feeding their child too much. To overcome this, increased emphasis in health education should be given to the problem of overnutrition.

Mothers had high levels of general knowledge about healthy eating. This knowledge did not predict the quality of the children's diet score in the present study. This does not mean that dietary knowledge is not important. Because most mothers had very high scores on knowledge, these factors cannot act as predictors in a statistical model. However, it suggests that providing additional information is unlikely to improve the children's diet. In contrast to general dietary knowledge, awareness of specific dietary recommendations was lower and was significantly associated with poorer diet. Many mothers felt confused about expert recommendations. The challenge for health education is to deliver accurate and consistent information in a way that mothers will use.

The present study has some limitations. It is a relatively small cross-sectional study of reported food behaviours among socio-economically disadvantaged mothers. The large confidence intervals on some of the odds ratios indicate the limited precision of several estimates. This reflects the small size of the study. However, the study was powerful enough to detect many significant associations in the univariate analyses, and the final regression model identified five factors which exerted independent statistically significant effects. An alternative approach to the study design would have been to compare socioeconomically disadvantaged mothers with those from affluent areas. However, we were concerned that differences in income might obscure the ways in which attitudes and beliefs influence behaviour. Our approach was to keep income constant and to contrast the attitudes and beliefs of mothers whose children had a poor diet with 


\section{Box 1 Types of interventions to improve children's diet}

Address knowledge gaps and misperceptions:

1. Emphasise the need to restrict high-fat/high-sugar foods.

2. Promote fish consumption.

3. Discourage consumption of processed meats.

4. Utilise media other than leaflets, such as television and radio.

Healthy weight:

1. Address over-consumption in health education.

2. Emphasise that a healthy diet will help control weight.

Expand the range of foods eaten in the household:

1. Provide mothers with free fresh fruit in nurseries and child centres.

2. Expand the range of foods covered by the healthy start voucher scheme.

3. Institute a national try-a-new-food campaign.

4. Encourage local radio and press to broadcast recipes for simple meals.

5. Coordinate education campaigns with supermarket special offer deals.

Food purchasing:

1. Promote planned purchasing so that simple meals can be made quickly.

2. Promote healthy alternatives to high-sugar/highfat snacks.

Food preparation and serving:

1. Clarify that healthy foods can be easily prepared.

2. Emphasise that healthy options are often cheaper.

3. Encourage the provision of breakfast daily.

Planning, control and self-efficacy:

1. Convince mothers that planning meals is important.

2. Encourage mothers to plan to provide a meal at a set time on a chosen day.

3. Reinforce the social benefits of eating together.

4. Persuade mothers to develop explicit strategies to help the child to eat rejected foods.

5. Persuade mothers to develop explicit strategies to reduce the consumption of high-fat/high-sugar snacks.

those whose children had a good diet. This identified the behavioural factors which could be acted on to improve diet. Such actions could complement government-level initiatives to increase the incomes of disadvantaged mothers.
In summary, the present study has highlighted several facets of mothers' beliefs, attitudes and behaviour which could be targeted in interventions designed help mothers improve their child's diet (Box 1). Interventions are required to promote more positive intentions to the preparation and serving of foods. The benefits of these behaviours to the child (improved diet, weight control) should be emphasised. Mothers could be encouraged to plan specific meals at which the family eats together.

\section{Acknowledgements}

Sources of funding: The study was supported by a grant from the Chief Scientist Office, The Scottish Executive Health Department (grant number CZH/4/205).

Competing interests: None of the authors have any competing interests.

Authors' contributions: I.K.C. - study design, supervision, analysis, interpretation of results, writing the report. K.K. - questionnaire design, interviewing participants, analysis, interpretation of results, editing the report. L.I. study design, analysis, interpretation of results, writing the report. W.L.W. - study design, analysis, interpretation of results, editing the report. V.S. - study design, analysis, interpretation of results, writing the report. K.P. - study design, interpretation of results, editing the report. P.W.S. study design, editing the report.

\section{References}

1. Mann JI (2002) Diet and risk of coronary heart disease and type 2 diabetes. Lancet 360, 783-789.

2. Goran MI, Ball GD \& Cruz ML (2003) Obesity and risk of type 2 diabetes and cardiovascular disease in children and adolescents. J Clin Endocrinol Metab 88, 1417-1427.

3. Bromley C, Sproston K \& Sheldon N (editors) (2005) The Scottish Health Survey - 2003. Edinburgh: Scottish Executive; available at http://www.scotland.gov.uk/Publications/2005/ $11 / 25145024 / 50251$

4. Gregory JR, Lowe S, Bates CJ, Prentice A, Jackson LV, Smithers G, Wenlock R \& Farron M (2000) National Diet and Nutrition Survey: Young People Aged 4 to18 Years. vol. 1: Report of the Diet and Nutrition Survey. London: The Stationery Office.

5. Inchley J, Todd J, Bryce C \& Currie C (2001) Dietary trends among Scottish schoolchildren in the 1990s. J Hum Nutr Diet 14, 207-216.

6. Ruxton C, Kirk T, Belton N \& Holmes M (1996) Relationships between social class, nutrient intake and dietary patterns in Edinburgh schoolchildren. Int J Food Sci Nutr 47, 341-349.

7. Nelson M, Erens B, Bates B, Church S \& Boshier T (2007) Low Income Diet and Nutrition Survey. vol. 2: Food Consumption and Nutrient Intake. London: The Stationery Office.

8. North K \& Emmett P, the Avon Longitudinal Study of Pregnancy and Childhood (ALSPAC) Study Team (2000) Multivariate analysis of diet among three-year-old children and associations with socio-demographic characteristics. Eur J Clin Nutr 54, 73-80.

9. Mrdjenovic G \& Levitsky DA (2005) Children eat what they are served: the imprecise regulation of energy intake. Appetite 44, 273-282. 
10. Turrell G, Hewitt B, Patterson C, Oldenburg B \& Gould T (2002) Socioeconomic differences in food purchasing behaviour and suggested implications for diet-related health promotion. J Hum Nutr Diet 15, 355-364.

11. Serra-Majem L, Ribas L, Pérez-Rodrigo C, García-Closas R, Peña-Quintana L \& Aranceta J (2002) Determinants of nutrient intake among children and adolescents: results from the enKid Study. Ann Nutr Metab 46, Suppl. 1, 31-38.

12. Hursti U-KK (1999) Factors influencing children's food choices. Ann Med 31, Suppl. 1, 26-32.

13. Contento IR, Basch C, Shea S, Gutin B, Zybert P, Michela JL \& Rips J (1993) Relationship of mothers' food choice criteria to food intake of preschool children: identification of family subgroups. Health Educ Q 20, 243-259.

14. Gibson E, Wardle J \& Watts C (1998) Fruit and vegetable consumption, nutritional knowledge and beliefs in mothers and children. Appetite 31, 205-228.

15. Longbottom P, Wrieden WL \& Pine C (2002) Is there a relationship between the food intakes of Scottish 5(1/2)8(1/2)-year-olds and those of their mothers? J Hum Nutr Diet 15, 271-299.

16. Hupkens C, Knibbe R, Van Otterloo A \& Drop MJ (1998) Class differences in the food rules mothers impose on their children: a cross-national study. Soc Sci Med $\mathbf{4 7}$, 1331-1339.

17. Falciglia GA, Couch SC, Gribble LS, Pabst SM \& Frank R (2000) Food neophobia in childhood affects dietary variety. J Am Diet Assoc 100, 1474-1481.

18. Koivisto U \& Sjödén PO (1996) Reasons for rejection of food items in Swedish families with children aged 2-17. Appetite 26, 89-103.

19. Birch LL (1998) Development of food acceptance patterns in the first years of life. Proc Nutr Soc 57, 617-624.

20. Savage JS, Fisher JO \& Birch LL (2007) Parental influence on eating behavior: conception to adolescence. J Law Med Ethics 35, 22-34.

21. Office of the Chief Statistician (2004) Scottish Index of Multiple Deprivation 2004. Technical Report. Edinburgh: Scottish Executive; available at http://www.scotland.gov. uk/Resource/Doc/26350/0025281.pdf

22. Ajzen I (1991) The theory of planned behavior. Organ Behav Hum Decis Process 50, 179-221.

23. Parmenter K \& Wardle J (1999) Development of a general nutrition knowledge questionnaire for adults. Eur J Clin Nutr 53, 298-308.

24. Bingham SA, Gill C, Welch A et al. (1997) Validation of dietary assessment methods in the UK arm of EPIC using weighed records, and 24-hour urinary nitrogen and potassium and serum vitamin $\mathrm{C}$ and carotenoids as biomarkers. Int J Epidemiol 26, s137-s151.
25. US Department of Agriculture (1996) What We Eat in America: 1994-1996. Diet and Health Knowledge Survey Questionnaire. Rockville, MD: USDA.

26. Shaw A, McMunn A \& Field J (editors) (2000) The Scottish Health Survey 1998. Edinburgh: Scottish Executive Health Department; available at http://www.sehd.scot.nhs.uk/ scottishhealthsurvey/sh81.pdf

27. Caroline Walker Trust (1998) Eating Well for Under-5s in Care. Report of an Expert Working Group. London: Caroline Walker Trust.

28. Scottish Executive (2006) Nutritional Guidance for Early Years. Food Choices for Children Aged 1-5 years in Early Education and Childcare Settings. Edinburgh: Scottish Executive; available at http://www.scotland. gov.uk/Publications/2006/01/18153659/0

29. Gatenby SJ, Hunt P \& Rayner M (1995) The national food guide: development of dietetic criteria and nutritional characteristics. J Hum Nutr Diet 8, 323-334.

30. Food Standards Agency (2008) The eatwell plate. http://www. eatwell.gov.uk/healthydiet/eatwellplate/?lang =en (accessed September 2008).

31. Watt RG, Dykes J \& Sheiham A (2001) Socio-economic determinants of selected dietary indicators in British preschool children. Public Health Nutr 4, 1229-1233.

32. Macintyre S (2007) Deprivation amplification revisited; or, is it always true that poorer places have poorer access to resources for healthy diets and physical activity? Int J Behav Nutr Phys Act 4, 32.

33. Stang J (2006) Improving the eating patterns of infants and toddlers. J Am Diet Assoc 106, Suppl. 1, S7-S9.

34. Clark HR, Goyder E, Bissell P, Blank L \& Peters J (2007) How do parents' child-feeding behaviours influence child weight? Implications for childhood obesity policy. J Public Health 29, 132-141.

35. Liem DG, Mars M \& De Graaf C (2004) Sweet preferences and sugar consumption of 4- and 5-year-old children: role of parents. Appetite 43, 235-245.

36. Patrick H, Nicklas TA, Hughes SO \& Morales M (2005) The benefits of authoritative feeding style: caregiver feeding styles and children's food consumption patterns. Appetite 44, 243-249.

37. Faith MS, Scanlon KS, Birch LL, Francis LA \& Sherry B (2004) Parent-child feeding strategies and their relationships to child eating and weight status. Obes Res 12, 1711-1722.

38. Vereecken CA, Keukelier E \& Maes L (2005) School food policy at primary and secondary schools in BelgiumFlanders: does it influence young people's food habits? Eur J Clin Nutr 59, 271-277.

39. Cason KL (2006) Family mealtimes: more than just eating together. J Am Diet Assoc 106, 532-533. 